\title{
Estado de exceção, gestão militarizada dos ilegalismos e as novas configurações da infâmia no Brasil contemporâneo
}

\author{
Carlos Henrique Aguiar Serra ${ }^{1}$ \\ Luís Antônio Francisco de Souza ${ }^{2}$
}

\begin{abstract}
Resumo: A presente comunicação pretende por em destaque a discussão sobre os padrões históricos da relação entre estado e sociedade no Brasil. Em outros termos, como pensar as formas históricas de governo das pluralidades sociais e políticas? Parte-se da constatação de que a sociedade brasileira desenvolveu um dispositivo jurídico-penal que reforça a distribuição desigual de poder e de prestígio e que há variações significativas nos padrões históricos da delimitação entre legal e ilegal, naquilo que Michel Foucault denominou de ilegalismos ou que Agamben definiu como liminaridade. Caberia hoje perguntar quem são os infames contemporâneos, quem são os inimigos. A hipótese central da comunicação pretende explorar esta conexão entre as diversas formas de punição e a constituição de novas infâmias. Para pensar o quadro mais amplo desta problemática, considera-se a tese da militarização da segurança como forma de gestão biopolítica que não elite o controle do crime por meio da violência na medida em que o estado, por meio de políticas públicas perversas, reivindica para si não apenas o monopólio legítimo da força física, como também exerce este monopólio pelo uso da violência. E toda uma nova fisionomia da punição está atrelada às velhas formas da violência: novos níveis de aviltação da infâmia. Os mecanismos militarizados e a punição disseminada se enquadram não mais no modelo puro e simples da eliminação do inimigo interno, mas numa ampla estratégia de gestão de riscos que demandam uma ampla articulação entre biopolítica e estado de exceção que apenas agora estamos procurando compreender melhor.
\end{abstract}

Palavras Chaves: Segurança Pública, Punição, Estado de Direito, Militarização.

\section{State of exception, militarized management of illegalities and the new configurations of infamy in contemporary Brazil.}

\begin{abstract}
This paper aims to highlight the discussion about the historical patterns of the relationship between state and society in Brazil. In other words, how can we think of the historical forms of governance of social and political pluralities? It is based on the observation that Brazilian society has developed a legal-penal system that reinforces the unequal distribution of power and prestige, and that there are significant variations in the historical patterns of legal and illegal delimitation, in what Michel Foucault called illegality or Agamben defined as liminality. It would be up to today to ask who are the infamous contemporaries, who are the enemies. The central hypothesis of the communication seeks to explore this connection between the various forms of punishment and the constitution of new infamies. In order to think about the broader picture of this problem, it is considered the thesis of the militarization of

\footnotetext{
${ }^{1}$ Professor do Departamento de Ciência Política e do Programa de Pós-Graduação em Ciência Política da Universidade Federal Fluminense (UFF). Doutor em História pela UFF.

${ }^{2}$ Professor do Departamento de Sociologia e Antropologia e do Programa de Pós-Graduação em Ciências Sociais da Unesp, campus de Marília. Doutor em Sociologia pela USP.
} 
security as a form of biopolitical management that does not elite the control of crime through violence insofar as the state, through perverse public policies, claims for if not only the legitimate monopoly of physical force, but also exercises this monopoly over the use of violence. And a whole new physiognomy of punishment is tied to the old forms of violence: new levels of debauchery of infamy. The militarized mechanisms and the widespread punishment no longer fit into the pure and simple model of the elimination of the internal enemy, but in a broad risk management strategy that demands a broad articulation between biopolitics and a state of exception that we are only now trying to understand better.

Keywords: Public Security, Punishment, Rule of Law, Militarization.

\section{Introdução}

"A guerra não é conjurada... uma frente de batalha perpassa a sociedade inteira, contínua e permanentemente." (FOUCAULT, 1999, p. 58-59)

"Essa é uma semana muito exitosa para a segurança pública do nosso estado. A intervenção federal começa a apresentar resultados positivos. Foram diversas apreensões, diversas operações bem sucedidas e essa, sem sombra de dúvida, foi a mais exitosa." General Richard Nunes, interventor e Secretário da Segurança Pública do Rio de Janeiro (Extra, 07/04/2018)

Na presente comunicação, pretende-se analisar as complexas relações existentes, no cenário político brasileiro contemporâneo, entre o Estado de Direito, punição, militarização da segurança e novos níveis de infâmia. Busca-se refletir sobre as aparentes incongruências entre a democracia e a securitização da sociedade brasileira. Para fazer esta análise, a comunicação toma os exemplos um dos aspectos da segurança pública no Rio de Janeiro, no contexto da intervenção militar e o processo crescente de militarização da sociedade brasileira.

O processo histórico que redundou nesta complexa e problemática situação é bem conhecido. Trata-se, neste momento, de retomar alguns pontos. A aprovação da Lei no. 8.072 de 25 de julho de 1990, conhecida como a Lei dos Crimes Hediondos, representou o marco simbólico do delineamento de uma política de segurança fundamentada na guerra e no inimigo. Esta Lei apresentou dispositivos legais que se fundamentam no princípio da lei e da ordem, segundo o qual o poder do Estado deve se contrapor à força da barbárie representada pelo crime. Apesar das alterações legislativas e pelos remendos de inconstitucionalidade, a Lei de Crimes Hediondos apontou para uma tendência de políticas de segurança apresentadas como resposta "democrática" às 
Revista NEP, Núcleo de Estudos Paranaenses, Curitiba, v.4, n.2, dez. 2018

demandas em favor da criminalização de grupos considerados "perigosos". A partir de então, aumentou, na sociedade brasileira, o clamor por mais rigor e duração das punições penais.

A produção do encarceramento em massa é um dos indicadores deste modelo de segurança que enfatiza o controle social e político dos subalternos na mesma medida em que se dá a liquidação dos direitos e garantias constitucionais. Com isso, novos regimes de verdade, agora amparados pela democracia, colocam a segurança num lugar de destaque em relação às antigas reivindicações dos movimentos sociais em torno da saúde, educação, emprego e moradia. Neste contexto, a expressão "segurança" passa a ter presença garantida em todos os fóruns de discussões e toma conta da opinião pública. Mantendo-se sob o guarda-chuva constitucional, a segurança pública se coloca como condição para a realização da dignidade humana ou dos direitos humanos. O mote desta transformação foi o modelo da segurança cidadã. Mas, do ponto de vista das práticas e dos discursos, a segurança é a chave para o acionamento de um modelo militarizado; além disso, a segurança reforça a centralidade do sistema penal para a gestão cotidiana da chamada violência urbana. Mais importante ainda, o Estado, maior violador de direitos humanos do país, acaba ganhando mais legitimidade em suas intervenções sistemáticas para a garantia da "ordem pública” (Machado da Silva, 2008;2013; Garland, 2008; Wacquant, 2008).

O quadro contraditório é bem conhecido. O Brasil possui a terceira maior população carcerária do mundo, atrás apenas dos EUA e da China. São 247 presos para cada 100 mil habitantes. Entre 1995 e 2016 a população carcerária do Brasil saltou de 150 mil para 600 mil presos. Um terço desta população é constituído por presos provisórios e o encarceramento de mulheres tem crescido a taxas ainda mais alarmantes. O quadro se completa com a criminalização da miséria e dos movimentos sociais, a conversão das periferias e das favelas em guetos, o massacre de jovens negros, o controle policial violento, o recrudescimento de chacinas e execuções sumárias, a degradação das instituições penais.

Em outros termos, a punição legal e a violência ilegal convivem no mesmo modelo constitucional e no mesmo arranjo institucional, como se fossem faces da 
mesma moeda. E a legitimação do castigo violento, do suplício dos corpos e da tortura, perpetrados que pelo Estado quer pelo chamado crime organizado só aumenta (Salla, 2012). A tendência é antiga, mas a recente intervenção militar na segurança pública do Rio de Janeiro deixou às escancaras esta tendência da violência do estado contra a população das comunidades, num novo nível de infâmia só visto na aparatosa ocupação do Morro do Alemão, em 2011, com cenas de mortes e corpos mortos se espalhando pelos jornais do mundo todo. A punição violenta, a punição ilegal, as chacinas, a letalidade policial e o cotidiano de violência e morte a que estão submetidos os cidadãos das comunidades cariocas atingiram um patamar que pode corresponder a novos níveis de descivilização das relações entre estado e sociedade no Brasil contemporâneo. Estamos, cada vez mais, nos acostumando com as cenas de barbárie que fazem parte do cenário mais amplo de desrespeito sistemático e de gestão biopolítica violenta do estado brasileiro. A aceitação tácita deste nível de infâmia e a ausência de medidas jurídicas efetivas para criminalização da violência contra a população subalterna coloca esta questão do papel desempenhado pelas estratégias de exceção na conformação da segurança no Brasil ${ }^{3}$. Formulando de maneira mais explícita, no Brasil contemporâneo, a segurança pública se converteu em condição para a democracia política (Serra \& Zaccone, 2012). A punição e o extermínio têm longa tradição na formação históricosocial brasileira, mas, nesta comunicação, pretende-se mostrar sua face contemporânea e suas contradições.

\section{Em busca de uma compreensão teórica.}

\footnotetext{
${ }^{3}$ Não é necessário fazer muitos exercícios para demonstrar o grau de violência e infâmia no Brasil contemporâneo. Chacinas. Disponível em: <http://www.terra.com.br/noticias/infograficos/chacinasbrasil/chacinas-brasil-10.htm>. Milícias: https://brasil.elpais.com/brasil/2016/07/21/politica/1469054817 355385.html>. Violência policial: < http://www.bbc.com/portuguese/noticias/2015/08/150813 violencia policial chacina lk>. Tribunal do crime: $\quad$ http://sao-paulo.estadao.com.br/noticias/geral,policia-prende-17-do-pcc-em-tribunal-docrime, $10000003679>$. Rebeliões em presídios: <https://oglobo.globo.com/brasil/rebeliao-em-presidiosdo-rio-grande-do-norte-deixa-ao-menos-10-mortos-20776548>. Cracolândia: <http://tudosobre.estadao.com.br/cracolandia>. <http://www.observatoriodeseguranca.org/node/5256>. Febem: $<$ http://www.observatoriodeseguranca.org/imprensa/febem> Acesso em: 23/04/2018.
} 
Revista NEP, Núcleo de Estudos Paranaenses, Curitiba, v.4, n.2, dez. 2018

Tendemos a compreender este retrato do Brasil na perspectiva de uma exceção que se torna regra (Agamben, 2004). A legalidade jurídica parece depender da violência e da ilegalidade, acionadas cotidianamente como dispositivos de controle social e de punição diferencial. Nessa biopolítica dos corpos insurgentes, o assassinato e a imobilização das massas não são vistas como violações do direito. O estado de exceção é ao mesmo tempo uma configuração da institucionalidade jurídica e uma tática geral de governo das multiplicidades sociais emergentes. Ele reforça o aparato autoritáriorepressivo dentro da lei ao mesmo tempo em que torna ambígua a fronteira entre legalidade e ilegalidade.

As características essenciais deste estado de exceção podem ser identificadas na emergência do conceito de disciplina, na obra de Michel Foucault (1987), sobretudo em relação às transformações que implicaram na passagem do suplício ao adestramento dos corpos no interior das propostas dos reformadores das prisões. A punição disciplinar passa a atravessar todas as instituições da sociedade no mesmo momento em que ela está em crise no interior das prisões. A crise da disciplina pulverizou as estratégias de punição ao mesmo tempo em que permitiu o acionamento dos antigos castigos físicos. A disciplina ainda se mantém central não apenas para reformar os indivíduos, mas como peça na gestão dos ilegalismos populares (Garland, 2008; Batista, 2002; Wacquant, 1999).

É um enigma, mas a punição, neste contexto, volta a assumir sua antiga face sagrada. As formas rituais do sacrifício, ou seja, os mecanismos propiciatórios permitem que a vítima sacrifical seja imolada para apaziguar os deuses sem que sua morte seja considerada assassinato. Quem imola também está isento das imputações jurídicas. A morte deixa de ser sentida como uma violência que requer reparação. A punição, em seu sentido sagrado, portanto, justifica uma violência ritual. Agamben (2004a) explora estas questões em seu conceito de Homo Sacer, aquele que é matável, mas não sacrificável. O estado de exceção seria, então, o espaço político em que a violência é justificável mesmo quando fere diretamente a norma legal. Assim, a violência torna-se o fundamento do estado soberano ao mesmo tempo em que define seu limite (Agamben, 2004; 2004a). A violência utilizada no "combate" ao criminoso tido 
Revista NEP, Núcleo de Estudos Paranaenses, Curitiba, v.4, n.2, dez. 2018

como "bandido" define a característica central do Estado na medida em que aciona mecanismos de guerra e de punição ${ }^{4}$.

O poder nas sociedades contemporâneas, portanto, está articulado num dispositivo que funde a gestão do risco e a estratégia guerreira. $\mathrm{O}$ alvo do poder moderno não é fazer morrer, mas sim fazer viver. Mas a morte, e a violência de uma forma geral, parece se constituir como alvo último, final e ao mesmo tempo evitável na configuração das sociedades contemporâneas. A morte foi normalizada, como diz Elias (2001, p. 30-31), nunca "antes na história da humanidade foram os moribundos afastados de maneira tão asséptica para os bastidores da vida social; nunca antes os cadáveres humanos foram enviados de maneira tão inodora e com tal perfeição técnica do leito de morte à sepultura." Que saberes são estes que autorizam, nas sociedades contemporâneas, a aceitação da morte e da violência como parte do jogo pela proteção à vida?

Um dos componentes destes saberes está ligado à pretensão de preeminência dos militares na gestão da força e dos riscos, em que a vida e a morte têm lugar de destaque. O dispositivo militar funda novas fronteiras, porosas e imprecisas entre viver e morrer. É nesse sentido que não há uma contradição entre a politização da morte e a estratégia de poder biopolítica. A punição, a violência policial e as condições degradantes que imperam nas prisões fazem parte do dispositivo militarizado. A militarização dos aparelhos do Estado demostra que o poder de morte se transforma sob um dispositivo de poder que valoriza a vida produtiva. O poder de morte, confiscado pela polícia e racionalizado pelo militarismo, é pensado como uma gestão da vida útil; por isso, a seletividade dos que são punidos e, no limitem, são mortos pelo Estado. Paradoxalmente, matar é um dispositivo de controle da vida (e não da morte).

As guerras já não se travam em nome do soberano a ser defendido; tratavamse em nome da existência de todos; populações inteiras são levadas a destruição mútua em nome da necessidade de viver. Os massacres se tornaram vitais. Foi como gestores da vida e da sobrevivência dos corpos e da

\footnotetext{
${ }^{4}$ A definição do inimigo é feita a partir da "negação da própria forma de existência", que pode e deve ser considerado como diante de real ameaça de aniquilamento. Nessa linha, a política se torna, para Schmitt, um espaço de enfrentamento belicoso entre amigo e inimigo, com a consequência de que apenas um pode sair vivo, pois é a existência do inimigo é razão da unidade política (Schmitt,1992, p. 52).
} 
Revista NEP, Núcleo de Estudos Paranaenses, Curitiba, v.4, n.2, dez. 2018

\begin{abstract}
raça que tantos regimes puderam travar tantas guerras, causando a morte de tantos homens. E, por uma reviravolta que permite fechar o círculo, quanto mais a tecnologia das guerras voltou-se para a destruição exaustiva, tanto mais as decisões que as iniciam e as encerram se ordenaram em função da questão nua e crua da sobrevivência... O princípio: poder matar para poder viver, que sustentava a tática dos combates, tornou-se princípio de estratégia entre Estados; mas a existência em questão já não é aquela - jurídica - da soberania, é outra - biológica - de uma população. Se o genocídio é, de fato, o sonho dos poderes modernos, não é por uma volta, atualmente, ao velho direito de matar; mas é porque o poder se situa e exerce ao nível da vida, da espécie, da raça e dos fenômenos maciços de população. (Foucault, 1985, p. 129)
\end{abstract}

O governo da população e a gestão da vida correm paralelamente à aceitação dos custos altos das mortes como estratégia de segurança. As sociedades ocidentais, na esteira do desmantelamento do estado de bem-estar social, têm investido no modelo de controle social pelo encarceramento, pela vigilância e pela liquidação de direitos, o que reforça a obsessão por segurança e por punição (Wacquant, 1999).

Neste sentido, toda uma indústria do crime e da insegurança emerge e se alimenta dos altos níveis dos riscos do capitalismo globalizado. Esta nova configuração daquilo que alguns autores chamam de modernidade tardia tem impacto no emprego e no mercado de trabalho, no crime organizado transnacional, na estrutura das cidades e no meio ambiente (Giddens, 2000). Elementos de controle social high-tech começam a se tornar parte da paisagem social e mesmo as novas "cidades globais inteligentes" só são possíveis na confluência do aumento dos gastos públicos com gestão da segurança e privatização dos serviços de vigilância, monitoramento e gestão da informação (Beck, 2010; Bauman, 1999 e 2003).

David Garland (2008) e Loïc Wacquant ( 2008) demonstram que há uma crise sem precedentes do sistema penal. Ocorreu a expansão das estratégias de controle do crime na modernidade tardia que conciliam as respostas ao crime na direção do endurecimento da pena e disseminação de mecanismos sutis de controle social. Esta é uma sociedade com altas taxas de criminalidade, com desinvestimento público em políticas sociais ou a transformação de políticas sociais em políticas penais, e com a sensação de que as instituições tradicionais da área da justiça criminal não funcionam. Há o declínio do ideal de reabilitação, endurecimento das punições, reinvenção da prisão, expansão da 
Revista NEP, Núcleo de Estudos Paranaenses, Curitiba, v.4, n.2, dez. 2018

infraestrutura da prevenção e repressão do crime, comercialização do controle do crime e disseminação de técnicas eletrônicas de vigilância ${ }^{5}$. Estas características não entram em contradição com o modelo militarizado da segurança. Uma guerra cujo escopo não poderia ser travado apenas pelos instrumentos militarizados, mas também por outras estratégias de poder que incluem formas de punição e de controle social dos corpos vulneráveis. A punibilidade dos pobres, o crescimento da população carcerária, políticas penais revestidas de discursos sociais e a vigilância eletrônica podem ser extensões da guerra por outros meios.

\section{A exceção que vira norma}

A Polícia Militar, principal corporação policial do país, responsável pelo policiamento ostensivo e preventivo, é organizada militarmente e subordinada, em última instância, ao Exército brasileiro. A discussão mais evidente sobre a militarização refere-se à definição dos crimes cometidos pelos policiais militares, em funções de policiamento, como crimes militares e, portanto, como transgressões disciplinares, submetidas a um código, a um processo e a uma justiça militar próprios. As dimensões preocupantes deste quadro remetem ao Massacre do Carandiru, que somente após 20 anos, começa finalmente a ser julgado. Mas o julgamento não coloca em questão a situação de estado de exceção, em que a impunidade parece não apenas certa, mas aceita publicamente. A militarização da segurança pode ser componente importante do desrespeito aos direitos dos cidadãos e da violência que ainda é paradigma das ações policiais na sociedade brasileira? (Souza, 2012) ${ }^{6}$

\footnotetext{
${ }^{5}$ Observa-se o apoio ao controle social disseminado e à adoção punições mais duras, no Brasil e em vários outros países (Caldeira, 2001; Wacquant, 1999).

${ }^{6}$ As instituições militares podem ser caracterizadas como instituições totais, desde que não façamos uso muito estrito do termo. Elas referem-se a um significativo fechamento em relação ao ambiente externo, processam mediante tensão entre mundo doméstico e institucional e entre o mundo do interno e da equipe dirigente. Além disto, o "novato", ao ingressar na instituição passa a sofrer "uma série de rebaixamentos, degradações, humilhações e profanações do eu. O seu eu é sistematicamente, embora muitas vezes não intencionalmente, mortificado. Começa a passar por algumas mudanças radicais em sua carreira moral, uma carreira composta pela progressiva mudança que ocorrem nas crenças que têm a seu respeito e a respeito dos outros que são significativos para ele" (Goffman, 2001, p. 24).
} 
Revista NEP, Núcleo de Estudos Paranaenses, Curitiba, v.4, n.2, dez. 2018

Embora as competências institucionais da polícia e das forças armadas sejam claramente diferentes, as zonas de fronteira sempre existiram e continuam existindo nos dias atuais. A polícia tem o papel de manter a ordem pública e a paz social, trabalhando contra o crime e na gestão dos conflitos sociais de forma permanente e com vigilância constante. Mas o exército, de outra forma, procura tem a função de manter a soberania contra a agressão e intervenção de um inimigo externo.

Neste sentido, as duas instituições pretendem garantir o monopólio estatal da força física por meio do uso legal, autorizado e proporcional das armas. Entretanto, embora a autorização para o uso da força seja uma característica fundadora destas duas instituições, é importante ressaltar que a polícia é caracterizada pela ausência do uso sistemático da força enquanto que e exército preconiza o uso da arma como instrumento dissuasório por excelência. Além do mais, a doutrina, armamento, instrução e treinamento da Polícia e do Exército são necessariamente distintos. A polícia não deveria aprender nem usar táticas de guerra, assim como o Exército não deveria ensinar ou usar técnicas de policiamento em contextos urbanos? Mas, em países como o Brasil, as competências policiais e militares não estão totalmente definidas. O país adotou um modelo de polícia que ainda está fortemente atrelado à defesa do Estado e não à defesa do cidadão. É um modelo híbrido no qual convivem uma polícia investigativa de caráter civil e uma polícia preventiva de caráter militar. No Brasil, "o processo de policialização das Forças Armadas ocorre simultaneamente ao de militarização da Polícia" (Zaverucha, 2005, p. 19) ${ }^{7}$.

A militarização, de certa forma, frustrou as expectativas de adoção de diretrizes para uma segurança consentânea à democracia e aos preceitos fundamentais das liberdades e proteções do estado de direito (Nóbrega Jr, 2010). O caminho para a profissionalização da polícia, assim como a vinculação das políticas de segurança

\footnotetext{
${ }^{7}$ Nos debates atuais sobre a definição de polícia e policiamento, não é mais e tão somente o uso da força que define a noção e a prática de polícia. A distinção entre polícia e forças armadas é feita na medida em que a primeira caracteriza-se pelo uso da informação, pela interdição do uso sistemático da força, corporificada na arma de fogo e pelo contato com o cidadão, destinatário de seus serviços. A segunda caracteriza-se pelo monopólio da força, pelo uso da arma de fogo como modelo de dissuasão e de desativação das ameaças e pelo isolamento em relação ao contexto e ao entorno de sua atuação. Mas, na prática, há evidente overlapping (Bayley, 2001; Lima, 1995).
} 
pública aos influxos e demandas por equidade da sociedade brasileira mais ampla, está dividido entre governo democrático da segurança e a lógica da guerra, tão insistente entre aqueles que defendem o combate a terrorismo e a guerra às drogas, como modelo a ser seguido no país. Em razão disto, coloca-se o debate em torno da mudança de paradigma das guerras modernas e do papel dos exércitos e das armas na consecução de uma ordem global armada que ainda pretende defender fronteiras e fluxos de riquezas. Há um grande mercado local e global que se alimenta da lógica militar e da força. O dispositivo de segurança militarizada reforça estas tendências na medida em que apela para os símbolos de poder militar, para a metáfora da guerra permanente ao inimigo interno e para a necessidade crescente de recursos financeiros disponíveis, bem como para a suspensão de direitos para consecução de seus objetivos ${ }^{8}$.

Não há mais guerra e paz, mas intervenção e segurança. As mudanças cruciais no mundo pós-queda do muro de Berlin e fim da guerra fria implicam na intervenção em outros países ou na ordem interna de determinado país. A intervenção é um mecanismo essencialmente militar, é a ponta armada de um dispositivo geral de segurança. A segurança não é essencialmente militar, pressupõe proteção, os meios para atingir a proteção e a condição das pessoas protegidas que são tomadas em sua condição de seres vivos. A segurança neste novo contexto pressupõe a minimização dos riscos, mas não dispensa os custos da morte. Os estados de violência recomendam a vigilância de cada um e a multiplicação dos limites territoriais. A segurança pública torna-se supraestatal e a guerra, local (Gros, 2006).

A partir dos anos 1990, houve um renovado ânimo para discutir o modelo de polícia no Brasil, a partir da proposta de unificação das duas polícias estaduais. Mas o debate chegou a um dead-end. O modelo de polícia militar continua fortemente atrelado à ideia de segurança nacional. As metáforas cotidianas ligadas à segurança são ainda militares: combater o crime, eliminar e derrotar o inimigo. O controle da droga e das armas ainda tem conexão com o modelo militarizado. As policias no Brasil são fortemente militarizadas e apresentam indicadores maiores de violência policial e de

\footnotetext{
8 Autores e pesquisadores internacionais, não obstante, insistiam na adoção de modelos civis e de gerenciamento democrático da segurança mesmo após os ataques de 11 de setembro de 2001 (Bayley, 2006; Johnston \& Shearing, 2003).
} 
Revista NEP, Núcleo de Estudos Paranaenses, Curitiba, v.4, n.2, dez. 2018

isolamento institucional. O militarismo, além de colocar a segurança como problema de Estado e defesa da soberania, reforça a dimensão policialesca de combate violento ao varejo do crime. O limite ainda é que a estrutura policial no país está constitucionalizada e qualquer mudança envolve muito esforço sem garantias de sucesso.

Outro importante indicador que aponta na direção do recrudescimento do debate dos modelos de intervenção e de segurança marcadamente militarizados no país são as guardas municipais. Timidamente disciplinadas no contexto constitucional de 1988, as guardas municipais sequer são citadas como órgãos de segurança pública no caput do artigo 144, que elenca os fluídos modelos de polícia judicial e militar como a polícia federal, a polícia rodoviária federal, as polícias civis, as polícias militares e corpo de bombeiros militares. É no parágrafo $8^{\circ}$. do artigo 144 , que a Constituição Federal fez alusão as guardas, atribuindo aos municípios sua criação e manutenção destinadas "à proteção de seus bens, serviços e instalações, conforme dispuser a lei"". Nesse sentido, as guardas municipais seriam uma espécie de força de vigilância e de proteção do patrimônio público, um sentido expresso na própria apreensão da expressão de "guarda" daquilo que pertence ao mundo público.

O debate em torno da guarda municipal ganhou fôlego a partir da atribuição de poder de polícia. Os municípios, apoiados na possibilidade de criação de leis orgânicas para legislar sobre assuntos de interesse local, criam suas guardas, fazendo delas um instrumento de controle social e de uso político. A formação de guardas municipais, cuja justificação está cada vez mais apoiada na violência e da insegurança, amplia o horizonte da atuação policial voltada para os inimigos internos. Na esteira da função de guardiã dos interesses locais e força auxiliar das polícias, as guardas municipais são investidas a partir do modelo policial consolidado no país. A pauta de discussões da formação destas guardas oscila, de modo geral, entre um desenho de uma polícia comunitária (entendida como mais próxima da comunidade) e debates sobre o tipo de

\footnotetext{
${ }^{9}$ Art. 144. A segurança pública, dever do Estado, direito e responsabilidade de todos, é exercida para a preservação da ordem pública e da incolumidade das pessoas e do patrimônio, através dos seguintes órgãos: (...)

$\S 8^{\circ}$ - Os Municípios poderão constituir guardas municipais destinadas à proteção de seus bens, serviços e instalações, conforme dispuser a lei. Constituição da República Federativa do Brasil, 2014.
} 
Revista NEP, Núcleo de Estudos Paranaenses, Curitiba, v.4, n.2, dez. 2018

armamento usado, regimento disciplinar e hierarquizado, bem como a atribuição de poderes em relação ao trânsito, ao patrimônio e aos direitos individuais e coletivos.

A publicação do Estatuto Geral das Guardas Municipais ${ }^{10}$ procura disciplinar a matéria e deixa poucas dúvidas em relação ao seu caráter policial: as guardas são “instituições de caráter civil, uniformizadas e armadas conforme previsto em lei, com a função de proteção municipal preventiva, ressalvadas as competências da União, dos Estados e do Distrito Federal". O elenco de funções das guardas é ambivalente, pois alia proteção dos direitos humanos, exercício da cidadania e das liberdades públicas, preservação da vida, patrulhamento preventivo, uso progressivo da força. A ambivalência persiste na medida em que a lei autoriza porte de arma, representatividade no Conselho Nacional de Segurança Pública, pacificação de conflitos e vigilância local, colaboração com as demais forças policiais, atuação frente à segurança escolar, articulação com os órgãos municipais visando a adoção de ações interdisciplinares de segurança. As mudanças recentes sinalizam um esgotamento do estoque de ideias novas na segurança. A tendência continua na direção de um reforço da militarização ou de estratégias militarizadas de segurança.

\section{Gerindo a segurança por meio de intervenções militares}

A experiência das intervenções de segurança pública no Rio de Janeiro é exemplar em relação a esta situação de uma militarização crescente da segurança aliada ao aumento da violência do estado sobre comunidades periféricas. Grande parte das justificativas para as intervenções gira em torno do chamado crime organizado e do tráfico de drogas. Afinal, estamos diante de uma nova onda de militarização da segurança pública no Brasil ou mesmo de uma "militarização do campo social"? Várias mudanças no cenário recente da segurança pública no país podem ser ponto

\footnotetext{
10 Trata-se da Lei no. 13.022 de 08 de agosto de 2014. Disponível em http://www.planalto.gov.br/CCIVIL_03/_Ato2011-2014/2014/Lei/L13022.htm. Acesso em 28 de setembro de 2014.
} 
de partida para a discussão. As forças armadas podem fazer atividades policiais como revistar pessoas, veículos, embarcações, bem como podem deter pessoas consideradas suspeitas em áreas de fronteira. O Brasil tem investido menos em instituições permanentes e civis de segurança e mais em instrumentos de intervenção pontuais, cuja definição, identidade, estatuto jurídico e formas de controle são ambivalentes ${ }^{11}$.

A Força Nacional de Segurança é um exemplo de intervenção militarizada em situações de crise na segurança, como greves de policiais, conflitos entre forças policiais e milícias ou ataques por parte do chamado crime organizado. A Força Nacional tem assumido papel de polícia permanente em vários estados brasileiros: no DF ela faz a fiscalização do chamado contorno; nas fronteiras, em áreas indígenas e em assentamentos está atuando de forma recorrente ${ }^{12}$. Oficiais das Forças tem presença significativa nas agências de inteligência e nas instituições da segurança, assim como policiais militares têm presença garantida em diferentes instâncias da administração pública, incluindo os municípios. Os militares nunca deixaram o espaço da política e ainda ocupam posições importantes na burocracia estatal, nos três níveis de governo. Importante lembrar que esta não é uma tendência restrita ao Brasil, vários países estão organizando suas polícias de forma militarizada, sempre com a justificativa da luta contra o terrorismo, contra o crime organização transnacional ou contra o poderio de fogo das organizações criminosas (Nobrega Jr, 2010). As forças militares brasileiras têm desempenhado papel na estabilização social e política do Haiti.

\footnotetext{
${ }^{11}$ Os militares estão de volta ao Rio de Janeiro, mas não deixado a cidade por muito tempo. Nos últimos 12 meses, os militares foram chamados 4 vezes para intervir no local. Ao longo da última década, o estado do Rio recorreu às Forças Armadas 12 vezes. Quem circula pelas ruas da cidade, já se acostumou com a presença de homens em uniformes camuflados, atiradores de elite, carros blindados e diversos outros personagens normalmente associados a palcos de guerra.

Disponível em: <https://www.opendemocracy.net/democraciaabierta/manoela-miklos-tomazpaoliello/militariza-o-da-seguran-p-blica-no-rio-e-em-todo-o->. Acesso em: 22/04/2018.

${ }^{12}$ A existência da Força Nacional de Segurança ainda é objeto de polêmica, sendo que sua criação e atuação são consideradas por muito como inconstitucionais. <https://jus.com.br/artigos/37331/a-inconstitucionalidade-da-forca-nacional-de-seguranca-publica> . Acesso em: 20/04/2018.
} 
Revista NEP, Núcleo de Estudos Paranaenses, Curitiba, v.4, n.2, dez. 2018

A segurança dos grandes eventos internacionais foi planejada e contou com a presença ostensiva das Forças Armadas. Apenas como ilustração: a Copa das Confederações contou com uma operação militar de defesa formada por 23 mil militares das três Armas e um investimento de R\$ 710 milhões. (O Estado de S. Paulo, 15/06/13); pelo menos 10 mil militares e 6,5 mil policiais militares fizeram a segurança do Papa Francisco na Jornada Mundial da Juventude (Folha de São Paulo, 09/07/2013). O Governado da Bahia mobilizou o Exército, juntamente com a Polícia Federal, a Polícia Rodoviária, a Secretaria de Segurança Pública e o Ministério Público, para combater os assaltos na saída dos bancos durante greve da polícia. (Correio Braziliense, 19/06/2013); As forças de reserva acabam ficando permanentemente em alerta para atuação de policiamento cotidiano e regular. Os militares fazem a segurança dos principais prédios do governo brasileiro em Brasília para garantir a segurança e evitar a depredação, durante as manifestações de junho de 2013. (Correio Braziliense, 21/06/2013; Folha de S. Paulo, 21/06/2013; O Estado de S. Paulo, 20/06/2013). Esta tendência é antiga e vem se tornando norma. Desde as intervenções militares da Eco-92, são constantes os apelos aos militares para garantir a segurança, como ocorreu em 2014, na Copa do Mundo e em 2016 nas Olimpíadas do Rio de Janeiro ${ }^{13}$. Não obstante, os indicadores de violência criminal continuaram sua tendência de crescimento (Destaque, 18/04/2018; Brasil de Fato, 23/02/2018). Não podemos esquecer que em 2017, o Exército brasileiro protagonizou uma intervenção nas favelas da Maré e no Morro do Alemão que custou aos cofres públicos mais de 01 bilhão de reais (Estado de São Paulo, 18/08/2017)14.

\footnotetext{
${ }^{13}$ As intervenções forma normatizadas e normalizadas por meio das chamadas GLO (Garantias de Lei e Ordem). As ações para "Garantia da Lei e da Ordem" são previstas no artigo no 142 da Constituição Federal e são regulamentadas pela lei complementar $n^{\circ}$ 97, de 1999, e pelo decreto presidencial 3.897, de 2001. Segundo a legislação, essas ações preveem a utilização das Forças Armadas em situações em que houver o entendimento que as forças policiais locais não são mais capazes de lidar com uma determinada crise. É claro que se trata de uma monstruosidade jurídica a legitimar o estado de exceção.

${ }^{14}$ Rio de Janeiro chama o exército pela $12^{\mathrm{a}}$ vez em dez anos. Disponível em: $<$ https://noticias.uol.com.br/cotidiano/ultimas-noticias/2017/07/29/rio-chama-exercito-contra-violenciapela-12-em-10-anos-virou-rotina.htm>. Acesso em: 23/04/2018.
} 
Revista NEP, Núcleo de Estudos Paranaenses, Curitiba, v.4, n.2, dez. 2018

A intervenção militar de fevereiro de 2018, em que, pela primeira vez na história do pais há, de fato e de direito, um interventor militar sobre a segurança pública, caminha nesta direção. É uma mistificação autoritária achar que o poderia militar de 36.000 homens em armas poderá produzir qualquer efeito duradouro a não ser a necessidade da duração infinita de novas intervenções. De fato, estamos diante de um estado de exceção permanente. As ações militares são espalhafatosas, mas os resultados são pífios, e, em geral, apenas são estratégias para fazer a gestão da pobreza numa das cidades mais desiguais do país, como forma de garantir, pela força, um exercício e uma sucessão políticos ilegítimos.

Estas estratégias de intervenção ficam patentes a cada incursão das forças policiais da exceção, como foi o caso da prisão de mais de 150 pessoas num pagode sob a justificativa de se tratar de uma festa de milicianos (Folha de São Paulo, 22/04/2018). A intervenção, portanto, decorre de uma tendência de militarização da segurança pública. E esta militarização está se prestando a violar direitos de cidadania, sobretudo quando coloca as populações dos morros e periferias em estado de sítio, sendo comuns as tentativas ilegais de revista sistemática, invasão de domicílios, prisões arbitrárias e até mesmo identificação em massa não autorizada pela lei ${ }^{15}$. Sendo assim, a militarização da segurança está contribuindo para elevar os níveis de infâmia dos moradores de periferia porque veem seus corpos cada vez mais incircunscritos (Caldeira, 2001). Mesmo tendo uma face abertamente ilegal, as intervenções militares na segurança são vestidas de

\footnotetext{
15 “Apesar da intervenção federal no Rio ser algo inédito desde a promulgação da Constituição de 1988, não é a primeira vez que as Forças Armadas realizam operações na área de segurança pública do estado. Os decretos de Garantia da Lei e da Ordem (GLO) foram usados por todos os ex-presidentes desde Fernando Collor, para permitir patrulhamento do Exército durante grandes eventos, como a ECO-92 e, mais recentemente, Copa do Mundo e Olimpíadas, ou para auxiliar as forças de segurança estaduais na tentativa de conter a violência de facções criminosas. Os índices de violência, como a taxa de homicídios, no entanto, sempre retomaram aos mesmos patamares, como 40 assassinatos por 100 mil habitantes, número de 2017. Um exemplo do desperdício de recursos públicos se seu, por exemplo, entre abril de 2014 e junho de 2015, quando o complexo de favelas da Maré, zona norte do Rio, permaneceu ocupado por militares do Exército, ao custo estimado de R\$ 600 milhões, sem produzir efeitos positivos na violência da região. Em 2017, foi a vez de Temer bancar R\$ 10 milhões em uma invasão na Rocinha que resultou numa pequena apreensão de armas." Disponível em: <https://www.brasildefato.com.br/2018/02/23/intervencao-militar-na-seguranca-do-rio-atinge-os-maispobres-e-nao-resolve-violencia/>. Acesso em: 23/04/2018.
} 
Revista NEP, Núcleo de Estudos Paranaenses, Curitiba, v.4, n.2, dez. 2018

legalidade a partir de ajustes legislativos infraconstitucionais que são, no mínimo, preocupantes, sobretudo no que diz respeito à tentativa de furtar o julgamento de crimes cometidos por militares em função de polícia da justiça comum ${ }^{16}$.

O modelo das UPPs fazia parte de um projeto de engenharia social mais amplo que contava, em sua origem com intervenções policiais e sociais articuladas. Mas, sempre bom lembrar que "a extensão 'social' do programa das UPPs 'militares', a qual, mesmo não estando a cargo da polícia, é pensada como um reforço necessário de combate ao crime". (Machado da Silva, 2013). Desde a implantação da primeira UPP em 2008 no morro Santa Marta até o ápice das intervenções, com características midiáticas e políticas evidentes em 2010 no complexo da Penha, a face social foi colocada para segundo plano e a face policial-militar se acentuou. Esta política pública que tem como foco o sufocamento do mercado ilegal de drogas, embora os discursos oficiais indiquem que o foco é o controle de armas e não das drogas, a partir da presença permanente da polícia no território das comunidades, substituindo as incursões inopinadas da polícia militar, vem passando por altos e baixos e provocado reações apaixonadas. Mas, não há para este modelo alternativa à vista, pelo contrário, em vários estados brasileiros, o modelo vem sendo adotado em versões mais ou menos genéricas, mesmo antes de uma avaliação mais criteriosa das estratégias do modelo pudessem ser realizadas.

De toda forma, não é o propósito deste trabalho fazer uma avaliação das UPPs em termos de sua eficácia e de seus custos sociais, políticos e institucionais. Pretende-se tão somente construir uma abordagem teórica no sentido da desconstrução de um certo consenso sobre as UPPs. Assim sendo, as UPPs se inscrevem na ótica dominante da política de segurança pública do Rio de Janeiro, que a partir do governo de Marcelo Alencar, com peculiaridades e singularidades, trazem pontos de contato: desde 1995, no Rio de Janeiro, os sucessivos governos estaduais optaram pela política do confronto, esta calcada no modelo bélico, na lógica do inimigo e mais, na sacralização da pena, na

\footnotetext{
16 "Foi com bastante perplexidade que a comunidade jurídica recebeu a Lei 13.491/2017, recentemente sancionada e que amplia a competência da Justiça Militar Federal e, como veremos, também da Justiça Militar estadual.” Disponível em: https://www.conjur.com.br/2017-out-20/limite-penal-lei-134912017fez-retirar-militares-tribunal-juri>. Acesso em: 20/03/2018.
} 
criminalização da miséria e numa política criminal de combate às drogas consideradas ilícitas, sob a chancela do derramamento de sangue, como afirma Batista (1998). Assim, a noção de pacificação merece uma problematização em termos de uma genealogia da pacificação. De fato, as etapas para implantação de novas UPPS no Rio de Janeiro são estruturadas em primeiro lugar como "intervenções táticas", em segundo como "estabilização" e, em terceiro, "implantação", com vistas à ocupação do território através da tomada de pontos críticos de armas e drogas.

O discurso oficial aponta para a pacificação como "arma" contra a violência e a centralidade do policiamento recai nos policiais fardados, formados nas academias militares, a despeito do discurso oficial indicar que as UPPs são tributárias do modelo de policiamento de proximidade. As conotações militares deste processo são evidentes e não precisam ser reforçadas (Rodrigue e Siqueira, 2012). No Brasil, não é novidade porque a lógica do inimigo, a fabricação incessante do outro como inimigo, inscrita na ótica bélica e militarizada. As UPPs são parte de um dispositivo punitivo e de extermínio, posto em funcionamento, e erigido sob a ótica de uma política de segurança pública, muito especificamente, no Rio de Janeiro, parar tornar o "combate" ao outro, com estratégia essencialmente de guerra.

Vera Malaguti Batista sustenta que "o fato das UPPs estarem restritas ao espaço de favelas, e de algumas favelas, já seria um indício luminoso para desvendar o que o projeto esconde: a ocupação militar e verticalizada das áreas de pobreza que se localizam em regiões estratégicas aos eventos desportivos do capitalismo vídeofinanceiro" (Batista, 2011, p. 02). A genealogia das UPPs nos ajuda a "esclarecer que o projeto não é nenhuma novidade, faz parte de um arsenal de intervenções urbanas previstas para regiões ocupadas militarmente no mundo a partir de tecnologias, programas e políticas norte-americanas que vão do Iraque à Palestina. No caso, o projeto de Medellín, foi este o paradigma. Governador e Prefeito para lá marcharam, sempre com os sociólogos de plantão, trazendo para o Rio de Janeiro um pacote embrulhado na 'luta contra o crime', sem que se percebesse que era um projeto de ocupação territorial apoiado pelo governo norte-americano contra a histórica guerrilha colombiana que chegou a ter $40 \%$ do território colombiano sob seu controle" (Batista, 
2011, p. 03). Segundo ainda a mesma autora, "O projeto das UPPs faz parte desse projeto de cidade que precisa aparecer como único, necessário, imprescindível, um uníssono que precisa muito do esplendor do Estado de polícia com seus símbolos: quem pacifica são os caveiras de camisa preta" (Batista, 201, p. 23).

No cenário atual, com a crescente onda de mobilização contra os governos do Estado e da cidade do Rio de Janeiro, já se pode perceber que alguns mitos, produzidos pelo projeto político das UPPs, em certa medida, começam a ser submetidos a um processo lento de desconstrução. Dois aspectos vêm sendo problematizados: 1) a política criminal contra as drogas: esta, desde o fim da guerra fria, tem a marca indelével da guerra e houve dramaticamente e tragicamente uma mudança identitária na construção do “inimigo". Esta política, que é genocida, de extermínio, que criminaliza a pobreza e a miséria, potencializa mais e mais a exclusão das camadas populares, não obstante dar sinais de esgotamento. A política das UPPS vai ao encontro desta política criminal de combate às drogas, com a marca do derramamento de sangue; 2) outro aspecto que vem sendo questionado diz respeito ao controle punitivo agenciado pelas UPPs, que se direciona exclusivamente às camadas populares e em grande medida tem as marcas do arbítrio e do autoritarismo (Batista, 2008; 2011; Machado da Silva, 2013). Os efeitos deste esgotamento são perceptíveis na retomada da violência policial, emoldurada pelos recentes casos de torturas e mortes de cidadãos dentro do território das UPPs.

As UPPs são expressões de uma racionalidade punitiva que agrega mais um capítulo ao rol dos discursos produzidos pela segurança publica brasileira. Nesse sentido, pensar estratégias que articulam uma política penal no Brasil passa por reconhecer a necessidade seu desenho a partir da publicização da função de controle social atrelada ao simbolismo de "justiça social" e da valorização da proteção paternalista do Estado, em que a função da segurança compreenderia o combate ou o enfrentamento da criminalidade como uma forma de resolver os problemas sociais que “desarmonizam” a convivência social. Assim, é possível refletir que a proposição de politicas penais (como as UPPs) pertence a uma "espécie de caleidoscópio de sentidos, de poderes e de saberes montada como uma forma de legitimar o discurso de um 
controle social democratizado por meio de uma imagem agradável aos olhos, ou seja, uma política de controle e de seletividade social legitimada na lei e pela lei, formando um sistema de segurança que seria capaz de responder simbolicamente aos medos e às desconfianças da população, ao mesmo tempo altamente opressoras com as camadas populares descartáveis”. (Gusso, 2013, p. 205)

Há um paradoxo contemporâneo no qual o Brasil encontra-se imerso: as contradições do Estado de Direito. Numa sociedade em que há uma sacralização da pena, na qual há, portanto, um verdadeiro clamor por penas ainda mais severas e rigorosas, sem dúvida alguma, os "direitos humanos" em questão não aparecem neste cenário com a devida e merecida indignação e gravidade de uma sociedade, profundamente desigual e hierarquizada (Freixo, Serra e Medeiros, 2012). A questão política da sacralização da pena se articula com a despolitização dos conflitos sociais, da violência, da criminalidade e por tais motivos, observamos com bastante intensidade o fenômeno da judicialização da política e, por conseguinte, o que encontra-se imbricado, o recrudescimento do aparato estatal punitivo que potencializa em larga a letalidade do Estado.

A desconstrução deste modelo representa um passo decisivo no sentido de se findar com a ótica da guerra, que reifica a cultura do inimigo, e, portanto, torna-se imperativo politizar os conflitos e a existência humana. Desta forma, um passo decisivo para esta desconstrução é a politização dos conflitos sociais e, portanto, um retorno urgente à Política enquanto atividade imprescindível à sociabilidade humana, pois, do contrário, continuaremos sob o império da lógica da guerra e da construção incessante de "inimigos" (Serra e Zaccone, 2012). Por outro lado, as intervenções das UPPs alteram aspectos importantes da vida das comunidades. A experiência deste tipo de policiamento de condutas não é fazia de sentido tanto para comunidade como para os policiais envolvidos, bem como para a rede e grupos que já atuavam nas comunidades antes mesmo das ocupações.

O que se pretende dizer aqui não é desconsiderar os efeitos imediatos do cessarfogo nas comunidades, nem desmerecer a enxurrada de projetos sociais que se seguiu ou se fortaleceu em razão da implantação das unidades. A pesquisa etnográfica tem 
detalhado estes efeitos e, inclusive, tem demonstrado os efeitos perversos dele em termos da expulsão de moradores em razão da valorização dos imóveis na comunidade e nas vias de acesso, o que abre, evidentemente, a discussão sobe os interesses econômicos que articulam a cidade ilegal e a cidade legal (Rodrigues e Siqueira, 2012). A pacificação é parte da lógica da guerra. Parte final, sem dúvida, mas a paz é processo contínuo de produção social e alimenta novas estratégias guerreiras enquanto houver os riscos. Sendo assim, a noção de pacificação pode ser entendida como um dispositivo discursivo que atualiza e legitima a passagem, no interior das comunidades "servidas" pelas UPPs, do modelo da vida sob "estado de cerco", para uma vida sob "estado de ocupação" (Machado da Silva, 2008; 2013).

\section{Considerações finais}

A presente comunicação pretendeu mostrar que a militarização é um fenômeno mais amplo e refere-se tanto à adoção de modelos, doutrinas, procedimentos e pessoal militares em atividades de natureza civil, quanto à mudança na configuração das guerras contemporâneas e ao papel das forças armadas. Ela envolve toda uma estratégia de gestão dos subalternos por estratégias tipicamente militares como também pelo uso puro e simples de mecanismos de segregação e violência.

As intervenções militares e as estratégias de militarização, neste sentido, operam a ampliação das margens onde se encontram o legal e o ilegal. "Todas as margens são perigosas”, já dizia Douglas (1976, p. 149). As margens, como a violência que emerge da ausência de um rito sacrificial, apontam para rituais seculares que "foram esvaziados de sentimento e significado (Elias, 2001, p. 36)". Diante da perda da significação e da violência banalizada, precisamos, portanto, seguir a recomendação de Michel Foucault e inverter a proposição de Clausewitz: a política é a extensão da guerra por outros meios.

As relações de poder estão encontrando sua ancoragem na guerra e nos dispositivos militares. O poder político insere estas relações nas instituições e as armas tornam-se os verdadeiros juízes (Foucault, 1999, p. 22-23). Em outros termos, já que o militarismo, além de representar o modelo de um estado de exceção, abre-se para toda 
Revista NEP, Núcleo de Estudos Paranaenses, Curitiba, v.4, n.2, dez. 2018

uma ritualística fúnebre, que potencializa a morte impune. Sendo assim, uma possibilidade interpretativa diz respeito à constatação de que, no Brasil, o Estado historicamente configura-se enquanto um aparato punitivo e que traz consigo, portanto, toda uma estratégia violenta imbricada à lógica do estado de exceção. E cabe à crítica mostrar seus perigos e suas continuidades.

\section{REFERÊNCIAS}

AGAMBEN, Giorgio. Estado de exceção. São Paulo: Boitempo, 2014.

AGAMBEN, Giogio. Homo sacer. O poder soberano e a vida nua. Belo Horizonte: Editora da UFMG, 2014a.

AGAMBEN, Giorgio. O reino e a glória. Uma genealogia teológica da economia e do governo. São Paulo: Boitempo, 2011.

BAUMAN, Zygmunt. Globalização: as consequências humanas. Rio de Janeiro: Jorge Zahar, 2003.

Comunidade. A busca por segurança no mundo atual. Rio de Janeiro: Jorge Zahar, 2003.

BATISTA, Nilo. Mídia e sistema penal. Revista Discursos Sediciosos. Rio de Janeiro: Revan, 2012.

BATISTA, Nilo e BATISTA, Vera Malaguti (Orgs). Paz armada. Rio de Janeiro: Revan, 2012.

BAYLEY, David. Padrões de Policiamento. São Paulo: EDUSP, 2001.

BAYLEY, David.Changing the guard. Developing democratic police abroad. Oxford: Oxford University Press, 2006.

BECK, Ulrich. Sociedade de risco. Rumo a uma outra modernidade. São Paulo: Editora 34, 2010.

CALDEIRA, Teresa Pires do Rio. Cidade de muros. Crime, segregação e cidadania em São Paulo. São Paulo. Edusp/Editora 34, 2001. 
Revista NEP, Núcleo de Estudos Paranaenses, Curitiba, v.4, n.2, dez. 2018

DE GIORGIO, Alessandro. A miséria governada através do sistema penal. Trad. Sergio Lamarão. Rio de Janeiro: Editora Revan, 2006.

DOUGLAS, Mary. Pureza e perigo. São Paulo, Perspectiva, 1976.

ELIAS, Norbert. A solidão dos moribundos. .Rio de Janeiro: Jorge Zahar, 2001.

FRADE, Laura. O que o congresso nacional pensa sobre a criminalidade. Brasília: Tese de Doutorado, UNB, 2007.

FOUCAULT, Michel. Segurança, território, população. São Paulo: Martins Fontes, 2008.

FOUCAULT, Michel. Em defesa da sociedade. São Paulo: Martins Fontes. 1999.

FOUCAULT, Michel. Vigiar e punir. O nascimento da prisão. Rio de Janeiro: Vozes, 1987.

FOUCAULT, Michel. História da sexualidade: A vontade de saber. Trad. $7^{\mathrm{a}}$. Edição. Rio de Janeiro: Graal, 1985.

FREIXO, Adriano de; SERRA, Carlos Henrique Aguiar e; MEDEIROS, Dulcinéa de. O Estado de direito no Brasil e suas incongruências: os direitos humanos em questão. Contemporânea: Revista de Sociologia da UFSCar, São Carlos, v.2, n.1, p.65-82, jan./jun. 2012.

GARLAND, David. A cultura do controle: crime e ordem social na sociedade contemporânea. Trad. Rio de Janeiro: Revan, 2008.

GOFFMAN, Erving. Manicômios, prisões e conventos. Trad. São Paulo: Perspectiva, 2001.

GROS, Frédéric. États de violence. Essai sur la fin de la guerre. Paris: Galimard, 2006.

GUSSO, Luana de Carvalho Silva. Carne e Culpa: notas sobre a gestão penal do sexo. Rio de Janeiro: Editora Lumen Juris, 2013.

JOHNSTON, Les \& SHEARING, Clifford. Governing security. Explorations in policing and justice. New York and London: Rutledge, 2003.

LIMA, Roberto Kant de. A Polícia da Cidade do Rio de Janeiro: Seus Dilemas e Paradoxos. Rio de Janeiro, Forense, 1995.

MACHADO DA SILVA, Luiz Antônio (Org.). Vida sob cerco: violência e rotina nas favelas do Rio de Janeiro. Rio de Janeiro: Nova Fronteira, 2008. 
MACHADO DA SILVA, Luiz Antônio. Cidades controladas. O controle do crime violento na cidade do Rio de Janeiro. Le Monde Diplomatique Brasil. Número 67. Fevereiro de 2013.

MACHADO DA SILVA, Luiz Antônio. Afinal, qual é a das UPPs? Disponível em: $<$ http://www.observatoriodasmetropoles.ufrj.br/artigo_machado_UPPs.pdf $>$. Acesso em: 03/ 2010.

MELOSSI, Dario e PAVARINI, Massimo. Cárcere e fábrica: as origens do sistema penitenciário. Rio de Janeiro: Revan, 2006.

NÓBREGA JR. José Maria Pereira. A militarização da segurança pública: um entrave para a democracia brasileira. Revista de Sociologia e Política. 18 (35). Fevereiro de 2010. p. 119-130.

RODRIGUES, André e SIQUEIRA, Raiza. As Unidades de Polícia Pacificadora e a segurança pública no Rio de Janeiro. In: Unidades de Polícia Pacificadora: debates e reflexões. Rio de Janeiro: Comunicações do ISER, número 67, ano 31, 2012.

SALLA, Fernando Afonso. Considerações sociológicas sobre o crime organizado no Brasil. Revista Brasileira de Ciências Criminais, v. 71, 2008.

SCHMITT, Carl. O Conceito de Político. Trad. Álvaro L. M. Valis. Petrópolis: Vozes, 1992.

SERRA, Carlos Henrique Aguiar e ZACCONE, Orlando. Guerra é paz: os paradoxos da política de segurança de confronto humanitário. In: Batista, Nilo e Batista, Vera Malaguti (Orgs). Paz armada. Rio de Janeiro: Revan, 2012.

SOUZA, Luís Antônio Francisco de. A militarização da segurança pública. Le Monde Diplomatique. 56, mar. 2012.

WACQUANT, Loïc. Les Prisons de la Misère. Paris, Éditions Raisons d'Agir, 1999.

WACQUANT, Loïc. "The Militarization of Urban Marginality: Lessons from the Brazilian Metropolis”. International Political Sociology, 2, 56-74, 2008.

ZAVERUCHA, J. FHC, forças armadas e polícia: entre o autoritarismo e a democracia, 1999-2002. Rio de Janeiro: Record, 2005.

Recebido: 10 set. 2018

Aceito: 16 nov. 2018 